\title{
Tomás Afán Muñoz, un artesano de la palabra
}

\section{Carlos Alonso Callero}

\section{(2) OpenEdition}

\section{Journals}

Edición electrónica

URL: https://journals.openedition.org/cher/1118

DOI: 10.4000/cher.1118

ISSN: 2803-5992

\section{Editor}

Presses universitaires de Strasbourg

\section{Edición impresa}

Fecha de publicación: 11 julio 2019

Paginación: 105-114

ISBN: 979-10-344-0046-1

ISSN: 1968-035X

\section{Referencia electrónica}

Carlos Alonso Callero, «Tomás Afán Muñoz, un artesano de la palabra», reCHERches [En línea], 22

2019, Publicado el 04 octubre 2021, consultado el 17 noviembre 2021. URL: http://

journals.openedition.org/cher/1118; DOI: https://doi.org/10.4000/cher.1118 


\title{
Tomás Afán Muñoz, un artesano de la palabra
}

\author{
Carlos Alonso Callero ${ }^{1}$
}

\begin{abstract}
A 1 hablar de Tomás Afán Muñoz (Jaén, 1968), hablamos de un "hombre de teatro", de hecho, nos encontramos ante uno de los autores más prolíficos, premiados y representados de su generación ${ }^{2}$, además de ser codirector, desde 1988, junto con Mari Carmen Gámez, de la compañía de teatro La Paca. Se caracteriza por ser un hombre reservado y reflexivo, pero también por ser un voraz observador de nuestra sociedad. Empezó siendo autodidacta, viéndose obligado a llevar adelante una compañía teatral, lo que le obligó a atender las diferentes facetas del hecho teatral: la actuación, la iluminación, la dirección, la producción y, por supuesto, la escritura dramática. (Anónimo 2017a). Todas estas facetas le fueron perfilando como un autor que escribe para la escena, que conoce su oficio.
\end{abstract}

Cada uno de estos roles influyeron en mi manera de concebir los textos. Nuestras características actorales, las limitaciones de los espacios escénicos a los que acudimos, las dimensiones de la furgoneta o las reacciones de los diversos

1 Carlos Alonso Callero, Departamento de Escritura y Ciencias Teatrales- Escuela Superior de Arte Dramático de Córdoba (España).

2 Premio de Teatro Luis Barahona de Soto, Premio Raúl Moreno FATEX (en 2 ediciones), Certamen Ciudad de Bailén, Premio ASSITEJ de Teatro para la Infancia y la Juventud (en 2 ediciones), Premio "Serantes" de Santurtzi (en 3 ediciones), Premio Sta. Cruz de la Palma, Premio Rafael Guerrero (en 5 ediciones), Premio Dulce por Amargo de la ESAD de Asturias, Premio Martín Recuerda (en dos ediciones) Premio Palencia de Teatro, Premi Castell d'Alaquas de Teatre, Premio Concurso de Monólogos del Cabildo de Gran Canaria (en 2 ediciones), Premio Hermanos Machado o Premio Monteluna, entre otros). Numerosas compañías de España y también de Italia, México, El Salvador, Perú, Chile, Puerto Rico, Nicaragua, Colombia, República Checa, Rep. Dominicana, Portugal, Cuba, Alemania, Brasil, Argentina, y Estados Unidos han representado sus textos entre los que destacan: Pim Pam Clown, Pictogramas, Esencia Patria, Parejas, El muerto más disputado, Atracción, Historias Cotidianas, En casa de muñecas, Los Impresentables... En producciones dirigidas por profesionales de la talla de Isidro Rodríguez, Carlos Alonso Callero, Andrés Beladiez, Fernando Bernués, Carlos Zabala, Esteban Sánchez, Mariano de Paco, Antonia San Juan, Michelle Guerra, Ainhoa Amestoy, Rolando Sanmartin, Pau Pons o Ramón Barea, entre otros. 
públicos ante mis obras precedentes, eran condicionantes que me vigilaban con gesto ceñudo, encaramados en mi hombro, mientras desarrollaba un nuevo texto. Poco a poco fui encontrando $\mathrm{mi}$ «voz». A veces monocorde, en ocasiones, engolada; aunque, con el tiempo, me apetecía probar nuevas tesituras, tonos y timbres, tratando, siempre, de no desafinar en todo este trayecto (empecé a escribir teatro en el año 1989) (Anónimo 2017a).

Hay un montón de nombres que le ayudaron a educar esa voz dramatúrgica, entre los que cabe destacar a Fermín Cabal, José Luis Alonso de Santos, José Sanchis Sinisterra, además de autores extranjeros como Fridhelm Grübe o April de Angelis. Hay que destacar que fue alumno de Sarah Kane y de Mary Peate durante el curso que impartieron en Sevilla en 1998, cuya maestría reconoce afable y humildemente.

Durante muchos años compaginó la interpretación, la dirección, la producción, la docencia, la gestión y otras tareas escénicas (incluyendo la carga y descarga) con la escritura teatral, aunque el transcurso del tiempo ha propiciado que la dramaturgia sea su ocupación fundamental y preferida. En cualquier caso, el experimentar el hecho teatral desde tantas perspectivas, ha condicionado y enriquecido, en gran medida, la elaboración de sus textos.

El poder experimentar en primera persona, como actor, director..., cómo las palabras, los personajes, las situaciones que ideé, en la soledad de mi escritorio, tenían que enfrentarse a la realidad de los ensayos, en primera instancia, y cómo culminaba su evolución en el encuentro con el público, suponía para mí una especie de laboratorio teatral continuo (Alonso 2018).

A la hora de encarar un texto como dramaturgo, Tomás Afán no tiene una táctica apriorística. A menudo experimenta y busca caminos diversos que le lleven a sitios diferentes, desarrollando esquemas y estructuras que le permitan descubrir caminos inexplorados. Le gusta aventurarse, jugar; algo que me parece esencial en el mundo de las artes escénicas. De hecho, en una de sus obras más conocidas, Historias cotidianas, que es la primera parte de un trilogía un tanto surrealista, puede verse un juego o búsqueda a la hora de acercar la cultura actual más pop al teatro, sin perder por ello la carga crítica y social que la sociedad requiere. Así, cabe atender al disparatado argumento de la obra:

Loli se ha comprado un hombre en oferta, y su amiga Margarita, por su parte, ha tirado el suyo a la basura, para comprarse uno de marca. Superman anda con la super-vista cansada, el pobre, y hay un presunto extraterrestre que jugaba con Dios a las canicas (cuando los dos eran chicos, claro). Y también salen psicópatas y fontaneros, la reina de la copla y el Presidente de los Estados Unidos; Antonia, que es la mujer de Superman, y hasta la Virgen María. En fin, pues eso... historias cotidianas... (Anónimo 2017a).

Esta trilogía se constituye de Historias cotidianas, que ganó el II Premio de Teatro Serantes de Santurce (2001), publicada por Serantes Kultur Aretoa de Santurtzi (Vizcaya), siendo estrenada en la Casa de la Cultura de Montefrío (Granada); también de una segunda obra, titulada Parejas, que ganó ex aequo al año siguiente el mismo premio, estrenada, en este caso, en el teatro Don Quijote 
(Consuegra, Toledo); y de Los impresentables, que obtuvo también este premio en su octava convocatoria (2007), publicada por Artezblai en 2008.

Cuando escribí esta obra, la realidad política imperante hacía que me sintiera un poco marciano, no me identificaba nada con las cosas que estaban pasando a mi alrededor a nivel social, y escribía desde el extrañamiento, tratando de desenfocar la realidad para volver a enfocarla desde otras perspectivas, con frecuencia, me gusta utilizar este tipo de juegos, y sí, la mayoría de las cosas que escribo las encaro desde una perspectiva absolutamente estéril de cambiar el mundo. Soy muy ingenuo (esta es una de mis varias características clowns), y creo fervientemente, aunque estoy absolutamente equivocado, que el teatro puede cambiar el mundo. Total, por intentarlo, no se pierde nada... si acaso la esperanza (Anónimo 2017a).

Yo como director de escena creo que el teatro no puede cambiar el mundo, pero me quedo contento con que alguna de mis puestas en escena puedan cambiar la vida o haga reflexionar a un solo espectador. Pero me gusta esa idea de Tomás, ya que por intentar mejorar nuestra sociedad, no se pierde nada, si acaso, como dice él, la esperanza. Precisamente, tuve ocasión de dirigir con motivo de su estreno en el Teatro Don Quijote la segunda obra de esta trilogía, Parejas, bajo la producción de 099 Producciones. He de agradecer a Anibal Fernández Lapeña, cofundador de 099 , la posibilidad, en varias ocasiones, que me ha brindado de entrar en contacto con la dramaturgia de Tomás Afán, ya que siempre ha apostado por trabajar con sus textos, y ya hemos llevado a la escena cuatro de ellos.

Parejas gira en rededor de las conexiones interpersonales, de las relaciones hombre-mujer, de la dependencia afectiva, de los arañazos emocionales, de la tan imposible como imprescindible relación de pareja. Son trece historias y son la misma historia, trece parejas distintas que viven de trece maneras diferentes la misma relación. Son él y ella de trece maneras, con trece posturas. Todo ello en clave de humor y con la ingenuidad como aliño. La acción se desarrolla en distintos escenarios tales como: un confesionario, la playa, un campo de fútbol, un parque, un campo de batalla. Relaciones sentimentales como las que viven un sacerdote y su apasionada admiradora en un confesionario, un tiburón seductor con una bañista, un delantero con la guardameta del equipo contrario, dos militares de ejércitos enemigos, una prostituta con un hombre del espacio, o un terrorista con su propia víctima.

El texto era tan sencillo y certero que fue un caramelo para mi trabajo como director. En Parejas emplea una estructura mediante pequeñas escenas con un hilo conductor, recurso que Tomás Afán maneja con gran maestría en diversas obras. Recuerdo con cariño aquellos ensayos. El texto, bien escrito y con esa facilidad del autor para el diálogo picado y vivo, la claridad en el planteamiento de los conflictos y ese punto surrealista que tiene la obra me ayudaron a estrenar un espectáculo que llegó a hacer más de doscientas funciones por toda España. Fue un gran éxito para la compañía manchega 099 y para todos los que trabajamos en ella. Un gran salto cualitativo en todos los sentidos. El público se moría de risa en cada representación. Eso dice mucho de lo que aporta el autor 
y lo fácil que me lo pone como director de escena. Y esa clave de comedia, sin tener que renunciar a mi idea poética del teatro, ni a mi concepto de belleza que siempre pongo en práctica en mis trabajos.

Para Tomás Afán Muñoz el oficio de la escritura dramática es lo más parecido a la hechicería que conoce:

uno garabatea una serie de palabras mágicas en un papel, y un tiempo después, esos sueños, esas imaginaciones, esos sortilegios que uno había escrito, se hacen realidad, uno entra en una sala oscura y descubre que sus letras se han convertido en voces, y sus verbos en acción (Alonso 2018).

En la tercera parte de esta trilogía, Los impresentables, hay una clara defensa de la libertad de expresión. Es una obra que trata sobre la provocación, pero no es provocadora. Sus protagonistas "son un grupo de autores y creadores que quieren revolucionar el arte y la cultura del siglo XXII (el XXI se les ha quedado ya chico), y para ello, investigan los límites, los extremos de lo que no se puede o no se debe decir" (Anónimo, sin fecha). Por lo que son, a veces, motivo de risa, dado el tratamiento que dan a algunos temas, por lo que cabe afirmar que, a la par, existe un interesante ejercicio de autocrítica a través de la parodia que Tomás Afán desarrolla en su propio discurso.

Sus protagonistas tratarán de urdir las historias más rompedoras, las tramas más transgresoras, derribando tabúes y haciendo de la provocación y el escándalo sus señas de identidad. El humor es el territorio de esta obra, que transversalmente trata temáticas generadoras de enorme polémica (violencia de género, terrorismo, símbolos sagrados islámicos, negación del holocausto, religión, ejército, etcétera) (Anónimo 2017b).

Su texto más representado es una obra que escribió para niños, Pim Pam Clown (La guerra de los payasos), que, de hecho, recibió el Premio Nacional ASSITEJ de teatro para la infancia y la juventud, y que luego han montado también para público adulto e incluso para la tercera edad. Pim, pam, clown forma parte de un experimento que realizó en el año 2002, con la intención de investigar en los personajes clowns, unos caracteres que le interesan mucho. Con tal finalidad realizó pequeños textos que combinaban las características del clown: ingenuidad, afán de imitación, fanfarronería, curiosidad, asombro, tomar las cosas al pié de la letra, vocabulario muy particular, especial relación con la autoridad y la poesía del clown, que desarrolló a lo largo de seis grandes temas, que cabe calificar de obsesiones creativas: el amor, el sexo, Dios, la muerte, la guerra y el fútbol (Afán 2015). De este modo, realizando todas las combinaciones posibles, durante casi dos meses, escribió 48 pequeñas piezas (una cada día). Las relativas a la guerra constituyen el núcleo principal de Pim pam clown, mientras que las referentes a Dios y a la muerte conforman otra obra editada: Criaturitas de Dios, y otras escenas de aquel trabajo están en otros textos encajadas con la lógica de su dramaturgia ágil y flexible desde mi punto de vista, como director, de algunas de sus obras.

Y aunque empezó escribiendo para niños, el público más difícil para los que nos dedicamos a la dirección de escena, pronto sintió el deseo de escribir para 
público adulto. Para nuestro autor, el camino es el mismo cuando se plantea escribir un texto para niños o para cualquier otro espectro de población. Lo fundamental en su caso, es encontrar una clave, un resorte, algo que le permita disfrutar a lo largo del viaje que emprende cuando se propone escribir un texto teatral. Ese disfrute (sin el cual es incapaz de culminar un proceso de escritura), puede residir en lo atractivo de una trama, que le apetece desarrollar o en unos determinados juegos de lenguaje, con los que se propone experimentar, o en un tema interesante que desea investigar. El caso es que estamos ante un escritor adulto (aunque ha preservado en buen estado ciertos restos arqueológicos de su infancia por los que le complace pasear a menudo), y en ocasiones puede sentirse un poco impostor (pese a tener tres niños pequeños) al atravesar, en sus textos, territorios de la infancia que les pertenecen únicamente a ellos. En cualquier caso, se esfuerza por tratar de mirar a las niñas y a los niños de frente, sin forzar la postura (ellos son más pequeños que el dramaturgo, y para mirarles de frente tendría que arrodillarse o elevarlos, y ambos esfuerzos suponen un lastre suplementario pero inevitable en la escritura).

Como director de escena, mi primer espectáculo infantil fue Especiales y puedo atestiguar y corroborar que su mirada hacia el público infantil es madura. Su texto, lleno de pequeñas historias de carácter didáctico fue muy bien acogido por el público, ya que trata a los niños desde una óptica respetuosa y seria. Esta obra nació como un encargo de Producciones 099 y Péndulo teatro, el objetivo que marcaron las compañías partía de una serie de premisas a nivel de dramaturgia que fueron planteadas al autor. El texto sería una obra para público infantil. La temática recogería las llamadas materias transversales. Para dos actrices y un actor. No debería requerir apenas escenografía, ni técnica, para poder ser transportado en un vehículo no muy grande. Por lo tanto los puntos fuertes de la función estarían en el texto y en el trabajo actoral. Y pese a tratar temas trascendentes el tono tendría que ser suficientemente divertido para mantener la atención del espectador.

El objetivo era tremendamente ambicioso: abordar en una misma obra la conciencia ecológica, la crítica al consumismo, la igualdad y el respeto entre sexos, la educación para la paz y la solución pacífica de los conflictos, la concienciación en hábitos democráticos, la educación para la salud, y en definitiva la tolerancia, la no discriminación y el respeto al distinto. En fin, un cúmulo considerable de premisas, que a priori, limitan bastante la libertad de acción a la hora de construir el texto teatral. En la entrevista que le he realizado por email con motivo de este artículo, sobre diferentes aspectos de su escritura, con respecto al teatro por encargo, me responde: "a mí, personalmente, a menudo las limitaciones me facilitan el camino, porque me ayudan a renunciar a lo superfluo, me conducen a un territorio de austeridad creativa, en el que me suelo encontrar muy cómodo" (Alonso 2018). Evidentemente, había que ir al grano, desarrollar muchos temas y muy delicados y complejos, y en la medida de lo posible, no caer en la tentación de moralizar en exceso. Para lograrlo, el tono sería necesariamente ligero. Era fundamental, sobre todo, divertir al espectador, hacerle pasar un buen 
rato, por tanto, del mismo modo que cuando se le va a dar una medicina a un paciente se la endulza para que resulte soportable, el humor y una cierta poesía servirían en este caso para hacer la obra digerible e incluso sabrosa. El teatro, desde mi punto de vista, junto con el de Tomás Afán, debe servir de plataforma de debate y de reflexión, y en este caso había que debatir y reflexionar sobre muchas cosas y la estructura por sketches, que él tan bien maneja, de nuevo era la forma más adecuada. Las historias se irían enlazando por el tono y por una estructura de pequeños monólogos, seguidos de diálogos que desarrollarían cada uno de los temas y los abordarían a través de distintas estrategias.

El primer segmento, titulado Mundo, enlaza no solo con el tema de la conciencia ecológica, sino con el objetivo genérico de la obra de servir como un análisis crítico del mundo en que vivimos y de la complicidad con los espectadores para intentar mejorarlo. Como Director de Escena encontrar un texto de Tomás es un alivio, porque me garantiza una sólida estructura. Eso mejora mi lectura contemporánea, pues el propio autor ya la ha hecho por mí. No tengo que hacer ninguna revisión, ni tocar su dramaturgia. A este dramaturgo le encargas algo y es un artista, pero también un artesano que conoce su oficio, por tanto, te da lo que necesitas como director: una buena historia que contar.

Personaje: Estoy limpiando mi bola del mundo con un trapo, pero no hay manera de que se le quiten los rayajos estos ¿Que qué rayajos? Estos. Creo que son los de las fronteras. Que funcionan como las puertas de los países, y que sirven para... separar unos países de otros... pero si no estuvieran los rayajos, sería más bonito porque la verdad es que estropean mucho los mapas, pero son muy difíciles de quitar... [Fragmento de Especiales].

La segunda historia, Super, trata el tema del consumismo desbocado a través de una hipótesis que desencadena el diálogo humorístico. La hipótesis es qué pasaría si se llegara a comercializar en los supermercados aire de marca para respirar: "Personaje 1.- En esta bolsa no hay nada. Aquí dentro lo único que hay es aire. Personaje 2.- Sí, pero es aire del que anuncian por la tele" [Fragmento de Especiales].

La tercera parte, "Modelos", introduce el tema de la anorexia y de los complejos en torno al físico, a través de unos diálogos bastante ingenuos, como los que maneja el clown, pues el autor considera que los payasos son un modelo perfecto a seguir para llegar a aceptarnos e, incluso, a reírnos de nuestras propias limitaciones. Esa idea del clown, me sirvió como director de escena del espectáculo para utilizar la nariz roja de payaso en todas las escena, aunque los intérpretes no tuvieran una gran base de clown, ya que lo uní a la idea de que cuando se colocaban la nariz se convertían en especiales, lo que le daba un relieve semiótico mucho más interesante a la globalidad de mi puesta en escena concreta y contemporánea.

Las siguientes historias, Héroes y Votos, tratan la igualdad hombre-mujer, y los hábitos democráticos a través de la ironía más afilada. Algo que como director es de agradecer ya que consigue dos lecturas. Una para los adultos y otra para los niños. Y por último, Combatientes y Especiales, que van sobre 
la educación para la paz y la no discriminación y el respeto al distinto, que cierran la obra con un humor más tierno que incluso deriva en una cierta poesía ingenua. Mi trabajo con el texto e intérpretes es sencillo, porque partimos de un texto literario-dramático claro e interesante. La materia prima, la elección del texto, es el momento más importante para un director.

En resumen, dirigir en aquella ocasión -por primera vez para mí- a este dramaturgo fue un descubrimiento. Sabía darle verdad a los diálogos y, además, se notaba que había pasado por todos los oficios, lo que resuelve bastante la labor de representación, ya que el autor ha pensado en la puesta en escena mientras escribía su pieza.

En cuanto a sus trabajos para público adulto, al principio, en sus primeros textos, escribía sobre los mitos, o eso intentaba, algo normal que han hecho autores como Heiner Müller o Rodrigo García. En principio le interesaban los estereotipos, los esquemas de géneros (dramáticos) y cierta dimensión épica. Le divertía subvertir la maquinaria de relojería que hacía funcionar determinadas tramas, le complacía reordenar esas piezas, dejando entrever trampas y resortes. Posteriormente, esa forma de trabajar fue dando paso a textos literariodramáticos en los que había cierto nivel de análisis social. Así, su dramaturgia fue poniendo su atención en la extrañeza con la que funcionan las cosas: la sociedad, el ser humano, pero, eso sí, a través del humor, explorando, al mismo tiempo, temas colaterales. Hay temáticas recurrentes en sus obras, como en cualquier dramaturgo que sea coherente con su universo: la muerte, el sexo, el fútbol, como ya vimos en Pim pam clown. El autor explica en la entrevista el porqué de estas obsesiones creativas:

Lo de la muerte supongo que es porque no me hace mucha gracia, y lo del sexo por todo lo contrario. Lo del fútbol, porque me parece una metáfora estupenda de nuestra sociedad, me encanta el fútbol como microcosmos con sus jerarquías, sus leyes, su sistema punitivo, sus banderas, uniformes e himnos, su lealtad ciega, su filosofía, su teología, es genial. Otros temas importantes en mis textos son: la religión, las relaciones de pareja, la manipulación (Alonso 2018).

Precisamente, en esta línea, cabe señalar Maduritos, otra de las obras de Tomás que dirigí con 099 Producciones. Abordar el tema de la madurez es complicado. Abordarlo desde los proyectos o sueños no cumplidos es doloroso. Pero si tres amigos de juventud vuelven a juntarse en el mismo gimnasio de hacía quince años, puede ser una pequeña bomba de melancolía y de risas. Reencuentros, esfuerzos para cambiar, vuelta a los conflictos pasados, frustraciones y $\ldots$ ¿A ti cómo te ha tratado la vida? ¿Qué fue de tus sueños?

Los personajes que nos cuentan esta historia son un funcionario, un especulador y un "sin oficio conocido", que sueñan con ser portada de las revistas de moda, cambiar el mundo desde la política, marcarle dos goles al Manchester United en la Final de la Copa de Europa, ganar un Óscar, dar la vuelta al mundo en bicicleta, tener un piso en propiedad y un largo etcétera. Esta vez, como director, me encuentro a personajes que se mantienen en escena con el mismo rol durante todo el espectáculo. Existe un arco del personaje, pequeños objetivos en cada escena y un superobjetivo final. Tres actores con buena disposición y que ya han 
trabajado conmigo en otros espectáculos. El texto está muy bien construido y ahonda en el fin de los sueños, en la crisis que implica la pérdida de juventud y de ilusiones.

El tema del paso del tiempo, como persona y profesional de la escena siempre me ha obsesionado. La nostalgia, el recuerdo, el olvido. El presente, el pasado y el futuro son muy importantes para analizar lo que le pasa a estos tres personajes. Tomás Afán construye bien estos diálogos. Me aporta una buena base para expresar toda mi pasión poética por este tema. Esta obra de teatro se estrenó en 2009 y estuvo en escena hasta el 2017. La recepción del público fue espectacular, lo que propició que hiciese más de cien representaciones. Un éxito. Y una evolución en mi relación con los textos de Tomás Afán, ya que por primera vez me enfrenté a una historia con continuidad en sus personajes.

En los últimos años, Tomás Afán Muñoz se encuentra en una etapa de indefinición, en la que emprende proyectos que le seducen, o encargos a los que les busca algo interesante (Anónimo 2017a). Uno de esos proyecto es Pictogramas, que nace como un encargo de la representante de una asociación de autismo de Jaén, que consideraba que el teatro podría resultar útil para mostrar la realidad del autismo a las personas que rodean a las chicas y chicos que tienen alguna de las características del espectro del trastorno autista: sus vecinos, sus conocidos, y sobre todo sus compañeros de clase (Anónimo 2017c). A partir de aquella premisa pasó dos años documentándose:

El título de la obra remite a esos dibujos esquemáticos que forman parte de la práctica cotidiana de las familias con miembros autistas. En la familia de Mujer, ilustradora de cuentos infantiles y madre de Ana y Pedro, hermanos y niños autistas, los pictogramas son una herramienta cotidiana para recordar las acciones que constituyen el día. Para una persona autista, nos recuerda Ana, el orden y la rutina son importantes: en las celdillas de los pictogramas están las tareas, los hechos destacados que dan confianza para afrontar el cotidiano (Pascual 2013).

Escribió diferentes historias breves que no permitía continuidad. Meses después retomó el proyecto, escribiendo nuevos textos breves, pero no conseguía encontrar un hilo conductor. El protagonista no se comunicaba a través de la palabra (tenía un autismo profundo), y Tomás se caracteriza por manejar magistralmente el diálogo de sus personajes con réplicas muy rápidas y dinámicas. Como aquello no acababa de funcionar, abandonó el proceso. Pero meses después, estimulado por la convocatoria de una nueva edición del Premio Assitej, se animó a retomar el texto literario-dramático. Y en aquel nuevo intento nació el personaje de la hermana de Pedro, el niño autista y protagonista, y aquello armó por completo la obra. Luego vinieron la madre y las escenas de los cuentos como leitmotiv vertebrador de la pieza. "El personaje de Ana tiene, en ese sentido, una función fundamental, para hacer preguntas claves al espectador, para evitar todo dramatismo fatuo" (Pascual 2013).

Por otro lado, el autor no quiso caer en el ternurismo, sin embargo era necesaria cierta dimensión poética que atravesara el texto. Finalmente, uniendo todas las piezas, la obra poseía suficiente unidad. El autor presentó Pictogramas 
al Premio Assitej, meses después recibió una llamada en la que le comunicaban que nuevamente había obtenido dicho galardón. Para el dramaturgo fue bastante emotivo visitar, un tiempo después, cuando la obra había sido editada, la Asociación de Autismo de Jaén para entregarle unos ejemplares del texto a la persona que le había lanzado la propuesta de escribir la obra. A la persona que le había preguntado si el teatro podía hacer algo para mejorar la situación de los niños autistas.

El epílogo de Pictogramas nos permite a los espectadores posicionarnos ante el futuro. Pedro toma la palabra para dirigirse a nosotros: nos plantea la existencia de una máquina traductora de los sentimientos de quienes no pueden expresar sus emociones. Una máquina transformadora [...] Aunque Pedro nos advierte que esa máquina traductora no existe, nosotros creemos que sí. Es el teatro (Pascual 2013).

Para mí, como director de escena, es de los textos más comprometidos y jugosos que he tenido entre las manos. Hay un término que lo definiría perfectamente: la alteridad. Pictogramas fue ensayada y montada en Canarias con dos actores de 099 Producciones. Era una forma de escapar del calor sofocante de la península ibérica y estar cerca de mi familia. El texto de Tomás, como se afirma, perfectamente, en la reseña, estaba perfectamente construido: "un estilo despojado de todo efectismo, Tomás Afán sabe dotar de verdad y profundidad a los personajes. Verdad, preguntas y acción. Nada hay en Pictogramas de mal teatro didáctico" (Pascual 2103). Pero tenía cinco personajes importantes en la trama y yo solo contaba con dos actores para hacerlo todo (el arte escénico y la precariedad). Tuve que adaptar el texto para que toda la historia se pudiese contar con dos personajes y a la vez no perder ni un ápice de la esencia de lo que quería contar el autor. Fue un trabajo difícil por esa labor de adaptación sobrevenida por las circunstancias. Aunque, al final, llegamos a buen puerto. Además de director soy dramaturgista, y me alegra poder afirmar que nuestro autor se ha quedado contento con el resultado. Pero ahora que tenemos la mejor pieza de Tomás, el tejido teatral de La Mancha y Andalucía está quebrado por la mala política cultural de estas regiones. Ya no vivimos los tiempos de cien funciones al año de un mismo texto. Pero esta obra es muy necesaria, es obligatorio para una sociedad incomunicada y decadente. Es una maquina transformadora:

Y gracias a la máquina esta puedo decirle: mamá, estoy bien, no te preocupes por mí. Te quiero. Aunque no sé cómo expresarlo. No encuentro una manera. La verdad... la verdad es que ni siquiera soy capaz de sentirlo, a veces. Pero te juro que me gustaría quererte. Muchísimo. Todo el tiempo. Sentir todo el cariño que sientes tú y que siente la gente por sus familias o por las personas que les importan [Fragmento de Pictogramas].

Como director artístico y jurado del Concurso de Monólogos del Cabildo de Gran Canarias, tuve de nuevo la ocasión de acercarme a nuevos textos de Tomás Afán. Ilusiones es un monólogo breve galardonado en la II edición de este concurso (2013), organizado por el Teatro Cuyás. Fue representado en la Sala Insular de Teatro de Las Palmas de Gran Canaria, 
con el resto de textos galardonados, bajo mi dirección. Recuerdo que ese texto era una ruptura con todo lo que había leído y trabajado de Tomás Afán anteriormente. Era un texto muy complejo, laberíntico, metafórico, pero fascinante. El tipo de pieza que me gusta como reto. Tuvo una gran acogida. El nuevo camino fue galardonado en la III edición del mismo concurso (2015) y representado en la misma sala, de nuevo bajo mi dirección. En palabras del autor:

En ambas piezas pretendía tratar de asomarme, a través de una visión no exenta de cierta poesía, a la perspectiva desalentadora de diversas personas víctimas de la precariedad: personas que han visto estallar en mil pedazos sus parcelas de confort, o que hurgan en los contenedores de basura para subsistir. La rebeldía femenina, me resultaba muy útil para agudizar el conflicto interno entre el personaje protagonista y su situación. Esta obra metateatral, además de intentar entablar un diálogo, desde la distancia en el tiempo, con la protagonista de la obra de Ibsen, persigue una reflexión sobre el medio teatral, una mirada a la realidad social, o una visión a la vez cruda e inocente del sexo, entre otros temas. Procurando que los cuatro protagonistas, con sus miserias y sus contradicciones, dejan entrever, no obstante, su humanidad, su vulnerabilidad, su voluntad de progresar, de mejorar (Alonso 2018).

En conclusión, estamos ante un autor que maneja muy bien los diálogos, que es un hombre de teatro y que por tanto escribe para la escena. Al manejar todos los elementos de significación del hecho escénico sus obras son muy certeras y agradecidas para los directores que trabajamos con su material. Asimismo, su obra, siempre, además de entretenida y arriesgada, tiene un trasfondo social que nos interesa a todos como colectivo. Gracias Tomás por poner tu granito de arena en la Dramaturgia española y extranjera.

\section{Bibliografía}

Afán Muñoz, T., 2015, "Cómo se hizo Pim pam clown", Textos para niños y jóvenes de Tomás Afán, <http://textosparapequesyjovenes.blogspot.com. es/2015/09/como-se-hizo-pim-pam-clown.html\#more $>$.

Anónimo, sin fecha, "Los impresentables. Mínima espacio escénico no convencional", Entrandium, <https://entradium.com/entradas/los-impresentables $>$.

Anónimo, 2017a, "Historias cotidianas. Tomas Afán, 2001", Contexto teatral, $<\mathrm{http}$ //www.contextoteatral.es/historiascotidianas.html>.

Anónimo, 2017b, "Los impresentable. Tomás Afán, 2007”, Contexto teatral, $<\mathrm{http}$ ://www.contextoteatral.es/losimpresentables.html>.

Anónimo, 2017c, "Pictográmas. Tomás Afán, 2011", Contexto teatral., <http:// www.contextoteatral.es/pictogramas.html>.

Alonso Callero, C., 2018, “Entrevista a Tomás Afán” [Inédita, realizada por email con motivo de este artículo].

Pascual, I., 2013, “Deslumbrante creación”, El Kiosko teatral, n 1, <http://www. aat.es/elkioscoteatral/leer-teatro/leer-teatro-1/jugando-al-teatro/>. 